\title{
Effects of Erythropoietin-Gene Electrotransfer in Rats with Adenine-Induced Renal Failure
}

\author{
Ken Ataka ${ }^{a}$ Hiroki Maruyama ${ }^{a}$ Tomohiro Neichib Jun-ichi Miyazakic \\ Fumitake Gejyo ${ }^{a}$ \\ a Division of Clinical Nephrology and Rheumatology, Niigata University Graduate School of Medical and \\ Dental Sciences, Niigata; bProduct Planning and Business Development, Chugai Pharmaceutical Co., Ltd, \\ Tokyo, and 'Division of Stem Cell Regulation Research, G6, Osaka University Medical School, Osaka, Japan
}

\section{Key Words}

Anemia associated with chronic renal failure $\cdot$ Gene therapy · In vivo electroporation - Muscle-targeted gene transfer. Plasmid

\begin{abstract}
Background: We previously demonstrated that erythropoietin (Epo) expression increases in five-sixths nephrectomized rats, after muscle-targeted gene transfer by in vivo electroporation, using plasmid DNA expressing rat Epo (pCAGGS-Epo). Here, we apply this method to a rat model with severe anemia associated with chronic renal failure; these rats have hematocrit levels in the $30-35 \%$ range, similar to those in humans with end-stage renal disease. Methods: Wistar rats were treated to produce adenine-induced uremia. The uremic rats were then treated with muscle-targeted gene transfer using pCAGGS-Epo. Some uremic rats died from chronic renal failure; one of these was dissected, and the kidneys were histologically examined. For the remaining rats, we measured body weight and blood pressure, and obtained blood samples regularly. Results: The uremic
\end{abstract}

\section{KARGER}

Fax +41613061234

E-Mail karger@karger.ch

www.karger.com
(C) 2003 S. Karger AG, Basel

0250-8095/03/0235-0315\$19.50/0

Accessible online at:

www.karger.com/ajn rats showed severe anemia, with hematocrit levels at $32.6 \pm 3.3 \%$. Epo-gene transfer increased Epo expression and serum Epo levels, and also increased the hematocrit levels to $64.5 \pm 4.8 \%$. The dose of pCAGGSEpo used in this study did not induce severe hypertension. Conclusions: Continuous Epo-gene expression improves the anemia associated with chronic renal failure, and without severe side effects. Our results support the potential use of gene electrotransfer for human gene therapy applications.

Copyright $\odot 2003$ S. Karger AG, Basel

\section{Introduction}

Anemia affects the great majority of patients who have end-stage renal disease (ESRD). Since its commercial release in 1989, recombinant human erythropoietin ( $\mathrm{rHuEpo}$ ) has permitted definitive therapy of this anemia. Epo is a survival factor for erythroid progenitor cells, preventing their apoptosis [1]. The raising of hematocrit levels with maintenance rHuEpo therapy has resulted in the improvement of a wide range of physiologic variables of 
ESRD and has had significant impact on patient morbidity, mortality, and hospitalization rates. Given the required frequency of the treatments and the high cost of the protein, a gene therapy protocol for the treatment of anemia in these patients would be of great advantage.

Various methods have been reported for improving the anemia associated with chronic renal failure (CRF) by Epo gene transfer. Hamamori et al. [2] used the transplantation of Epo-secreting myoblasts to treat the anemia of nephrectomized nude mice. Adenoviral [3], retroviral [4], and adeno-associated virus-based [5] vectors are also available for Epo gene transfer. However, these viral vectors may cause problems, including insertional mutagenesis, and apparent immunologic responses induced by the gene transfer. Simple injection of plasmid DNA encoding Epo into muscles also corrects anemia [6]. Furthermore, Aihara and Miyazaki [7] reported that in vivo electroporation provided an efficient approach for muscle-targeted gene expression. The level of gene expression was 100fold higher than that obtained by simple DNA injection into regenerating muscles.

We previously constructed the plasmid pCAGGS-Epo by inserting rat Epo cDNA into a unique Xho I site between the CAG (cytomegalovirus immediate-early enhancer/chicken $\beta$-actin hybrid) promoter and a 3'-flanking sequence of rat Epo cDNA [8]. We then demonstrated that in vivo electroporation of pCAGGS-Epo into rat muscle increases the level of Epo expression [8] and yields long-term production of significant amounts of Epo in the circulation [9]. Epo delivery by pCAGGS-Epo using in vivo electroporation also improved the mild anemia associated with CRF after five-sixths nephrectomy [9]. Rizzuto et al. [10] also showed that plasmid gene electrotransfer to surgically exposed muscles produced therapeutic levels of Epo.

To investigate whether in vivo electroporation can be applied to the improvement of severe anemia, we need an animal model that has hematocrit levels similar to those in humans with ESRD. Yokozawa et al. [11] showed that long-term feeding of adenine to rats produced metabolic abnormalities resembling CRF. Rats treated with adenine for 4 weeks showed severe anemia, with a hemoglobin concentration of $7.6 \pm 1.7 \mathrm{~g} / \mathrm{dl} 4$ weeks later [12]. A possible mechanism for this induction of renal failure is that the excretion of nitrogen compounds is suppressed by renal tubular occlusion due to 2,8-dihydroxyadenine crystals, leading to the accumulation of various guanidino compounds (such as methylguanidine and guanidinosuccinic acid) and urea nitrogen in the blood [11]. The degree of renal failure can be manipulated by the duration of ade- nine administration and the concentration of the adenine. A reportedly effective regimen is the administration of a $0.75 \%$ adenine diet for 4 weeks, which results in serum creatinine levels of $2.0 \mathrm{mg} / \mathrm{dl}$ [12]. Although approximately $20 \%$ of the rats fed adenine for 4 weeks die from CRF, this animal model has advantages, including the stable production and maintenance of uremic symptoms, and the development of the severe anemia associated with renal failure. We have used this rat model to study the pathophysiology of CRF in the present study. The major side effects of rHuEpo injection therapy in patients with ESRD are an increase in blood pressure, known as Epoinduced hypertension [13-17], and a decline in renal function $[18,19]$. Therefore, it is important to assess the physiological effects of Epo gene expression in a model of the severe anemia associated with CRF.

In this study, we treated the severe anemia associated with adenine-induced renal failure by continuous Epo delivery, using muscle-targeted gene transfer.

\section{Subjects and Methods}

\section{Plasmid Vectors}

Plasmid pCAGGS-Epo was constructed by inserting the rat Epo cDNA into a unique Xho I site of the pCAGGS expression vector [20], as previously described [8]. The empty pCAGGS plasmid was used as a control. Immediately before injection, the DNA was diluted in phosphate-buffered saline (PBS) to $2.0 \mu \mathrm{g} / \mu \mathrm{l}$.

\section{Intramuscular DNA Injection and Electroporation}

Muscle-targeted gene transfer by in vivo electroporation was performed essentially as previously described $[8,9]$. A total of $100 \mu \mathrm{g}$ of plasmid DNA, diluted with PBS, was injected into the lateral side of the lower flexor muscles. Injection was performed after shaving the hair. A pair of electrode needles was inserted into the muscle. The electrode consisted of a pair of stainless steel needles, $5 \mathrm{~mm}$ in length and $0.4 \mathrm{~mm}$ in diameter, with a fixed distance of $5 \mathrm{~mm}$ between them. The accuracy of the insertion into the muscle was confirmed by measuring the electric resistance between the two electrode needles, which was usually below $1,000 \mathrm{ohm}$. The dose of plasmid was decided from the results of our previous study [9]; we administered 10,40 , or $400 \mu \mathrm{g}$ of pCAGGS-Epo, and considered that Epo production levels were sufficiently induced by the amount of more than $30 \mu \mathrm{g}$, and much less than $400 \mu \mathrm{g}$ of the plasmid in uremic rats. Electric pulses were delivered by an electric pulse generator (Electro Square Porator; BTX, San Diego, Calif., USA), and monitored by a graphic pulse analyzer (MVC540R; BTX). Four 100-V, 50-ms electric pulses followed by four more pulses of the opposite polarity were administered to each injection site at a rate of 1 pulse/s.

\section{Rats}

Seven-week-old male Wistar rats were purchased from Charles River (Tokyo, Japan) and maintained under specific pathogen-free conditions in our animal facility. Eight rats were fed normal feed 
(Normal rats). Thirty-one rats were fed normal feed for 2 weeks and then a $0.75 \%$ adenine diet for 4 weeks [11]. They were then fed an adenine-free normal diet for 5 weeks (Adenine rats). Sixteen rats died from CRF. Gene transfer by in vivo electroporation was then performed on the remaining Adenine rats, which were divided into two groups according to the transferred plasmid, pCAGGS (Control rats; $\mathrm{n}=8$ ) or pCAGGS-Epo (Epo rats; $\mathrm{n}=7$ ).

\section{Total Tissue RNA Extraction and RT-PCR}

Five days after gene transfer, one each of the Epo rats and Control rats were sacrificed under diethyl ether inhalation. Their injected muscles were resected and frozen in liquid nitrogen. Total RNA from the muscle samples was isolated with Isogen (Nippon Gene, Osaka, Japan). Epo mRNA or glyceraldehyde-3-phosphate dehydrogenase (G3PDH) mRNA was detected by recombinant Thermus thermophilus DNA polymerase RT-PCR, using a High-Plus-Gyakuten-Ippatsu kit (Toyobo, Osaka, Japan). PCR was performed, using specific oligonucleotide primers, as follows:

Epo backward primer, 5'-GCCCAGAGGAATCAGTAGCA-3' Epo forward primer, 5'-TCTGACTGACCGCGTTACTC-3' G3PDH backward primer, 5'-TCCACCACCCTGTTGCTGTA-3 G3PDH forward primer, 5'-ACCACAGTCCATGCCATCAC-3'

We designed the Epo forward primer to hybridize with the sequence immediately downstream of the transcriptional start site of the CAG promoter. There is an intron between the CAG promoter and the Epo cDNA in pCAGGS-Epo. The primer set for detection of the Epo mRNA was designed to encompass intronic sequences, allowing us to distinguish any possible PCR products from contaminating plasmid DNA or genomic DNA. The primer set for detection of G3PDH mRNA was also designed to span introns. The cycle, temperature and length of the RT-PCR were adjusted as previously reported [8]. The RT-PCR products were analyzed by $4 \%$ agarose gel electrophoresis. The lengths of the expected products were $170 \mathrm{bp}$ for Epo mRNA and 452bp for G3PDH mRNA.

\section{Blood Parameters}

Rats were placed under general anesthesia, and blood samples $(2.0 \mathrm{ml})$ were obtained from the heart, according to the method of Ohwada [21]. The serum Epo levels were determined using a Recombigen EPO kit (Nippon DPC, Chiba, Japan) as described [9]. The number of reticulocytes was determined using a Sysmex R-3500 (Sysmex, Hyogo, Japan). Blood samples were obtained 1 week before, and 8 weeks after the start of the adenine diet, and at week 1, 3, 5 and 7 after in vivo electroporation (see fig. 3).

\section{Blood Pressure Measurement}

To evaluate the Epo-induced hypertension, we measured the blood pressure of the rats biweekly by the tail-cuff method, using a programmable sphygmotonometer (BP-98A; Softron, Tokyo, Japan); before taking the measurement, the rat was restrained in a rat-holder and warmed to $37-38^{\circ} \mathrm{C}$ [22]. The average of three consecutive measurements was used as the blood pressure.

\section{Tissue Preparation}

After the Adenine rats were sacrificed, the kidneys were removed, fixed in $4 \%$ paraformaldehyde, and embedded in paraffin. Thin sections were stained with hematoxylin and eosin (HE).

\section{Statistical Analysis}

Data are presented as mean \pm SEM values. All data were analyzed with a statistics software package, Stat-View Ver.5 (SAS Institute, Cary, N.C., USA). Statistical analysis was evaluated by the unpaired t test. $p<0.05$ was considered to be of significance.

\section{Results}

\section{Production of Rats with Adenine-Induced Renal Failure}

In this study, 31 rats were fed adenine at the beginning of the experiment. After 4 weeks, 16 rats had died from CRF. Before they died, almost all these rats showed abdominal distension. The 15 remaining rats were prepared as Adenine rats for gene transfer.

We dissected 1 of the Adenine rats that had died of CRF. There was a massive serous effusion around the kidney, enveloped in the capsule. The encapsulated effusion was palpable as a hard mass from the surface of the abdomen.

\section{Histological Examination of Rats with Adenine-Induced Renal Failure}

The kidneys were removed from the Adenine rats 8 weeks after the end of the adenine-feeding treatment. The kidneys were pale, and adenine crystals were seen mainly in the cortex area (fig. 1A). There was marked deposition of crystalline bodies in the renal tubules and interstitium (fig. 1B). The glomeruli, in contrast, did not show crystalline deposits. However, the glomeruli were observed sparsely. Renal tubular atrophy and severe interstitial fibrosis was also found. These findings are compatible with characteristics of CRF.

\section{RT-PCR Detection of Epo mRNA in Muscles Injected with $p C A G G S$-Epo}

The Epo mRNA was detected only in muscles injected with pCAGGS-Epo (fig. 2), but not in muscles injected with pCAGGS, while the control G3PDH mRNA was detected in both.

\section{Serum Epo Levels after in vivo Electroporation}

The serum Epo levels of the Epo rats increased significantly compared with the Control rats $(15.2 \pm 1.2 \mathrm{mU} / \mathrm{ml}$ at week 1). The Epo levels of the Epo rats peaked at $68.0 \pm 13.8 \mathrm{mU} / \mathrm{ml}$ at week 1 , and decreased gradually to $24.3 \pm 1.6 \mathrm{mU} / \mathrm{ml}$ at the endpoint of the experiment (fig. 3A). 

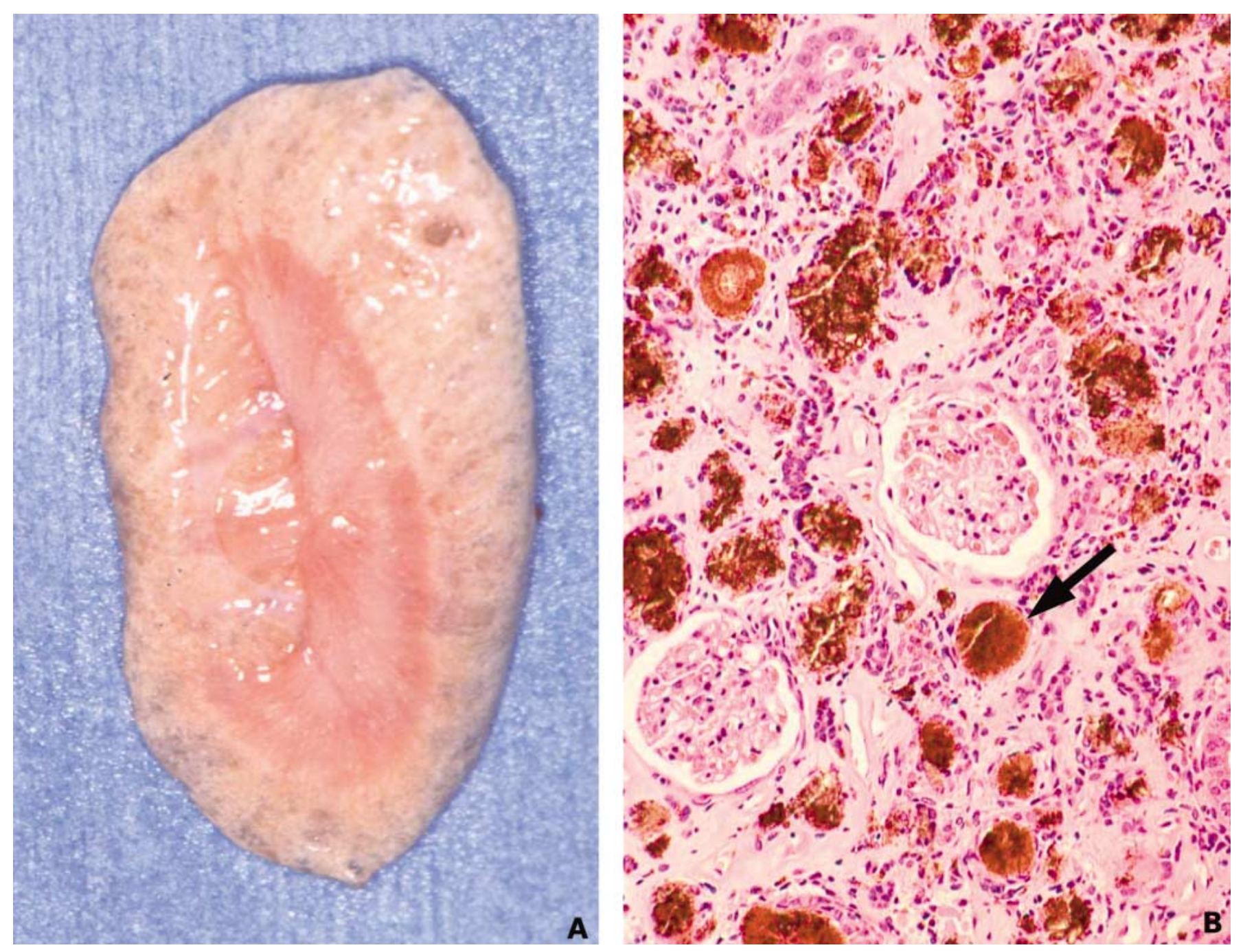

Fig. 1. A Macroscopic findings: Kidneys were removed at 8 weeks after the end of adenine treatment. The kidneys were pale, and crystalline deposits were seen mainly in the area of the cortex. B Histological findings: Crystalline deposits were mainly seen in the interstitial region (one of them is indicated by an arrow). Renal tubular atrophy and interstitial fibrosis were also found. HE. $\times 50$.

\section{Red Blood Cell Analysis}

Vector-derived Epo secretion caused reticulocytosis. Epo rats showed an increase in the number of reticulocytes (fig. 3B), which rose from the pre-injection levels of $31.9 \pm 6.1 \% 0$ at week -1 , peaked at $150.0 \pm 20.6 \% 0$ at week 1 ( $\mathrm{p}<0.001$ compared with Control rats), and decreased to levels of $45.0 \pm 15.4 \% 0$ at week 3 . (The elevation at week 3 was not significant.)

Adenine rats showed anemia associated with CRF, showed significant lower levels of hematocrit than Normal rats at pre-injection; $32.6 \pm 1.2$ vs. $51.0 \pm 0.6 \%$, respectively $(\mathrm{p}<0.0001)$. As the Epo secretion levels increased, hematocrit levels of the Epo rats increased to
$45.9 \pm 3.3 \%$ at week 1 after the plasmid injection, peaked at $64.5 \pm 2.8 \%$ at week 5 , and were maintained at $64.3 \pm$ $5.9 \%$ at week 7 after gene transfer, the endpoint of the experiment (fig. 3C).

\section{Platelet Counts}

The platelet counts of the Epo rats increased from preinjection levels of 104.3 ( \pm 7.7 ) $10^{4} / \mu 1$ to 131.2 ( \pm 5.8) $104 / \mu 1$ at week 1 , and subsequently decreased to 86.3 ( \pm 21.9 ) $10^{4} / \mu \mathrm{l}$ at week 7 . Although the increased levels were significant compared with Normal rats, they were not significant compared with the Control rats (fig. 4). 


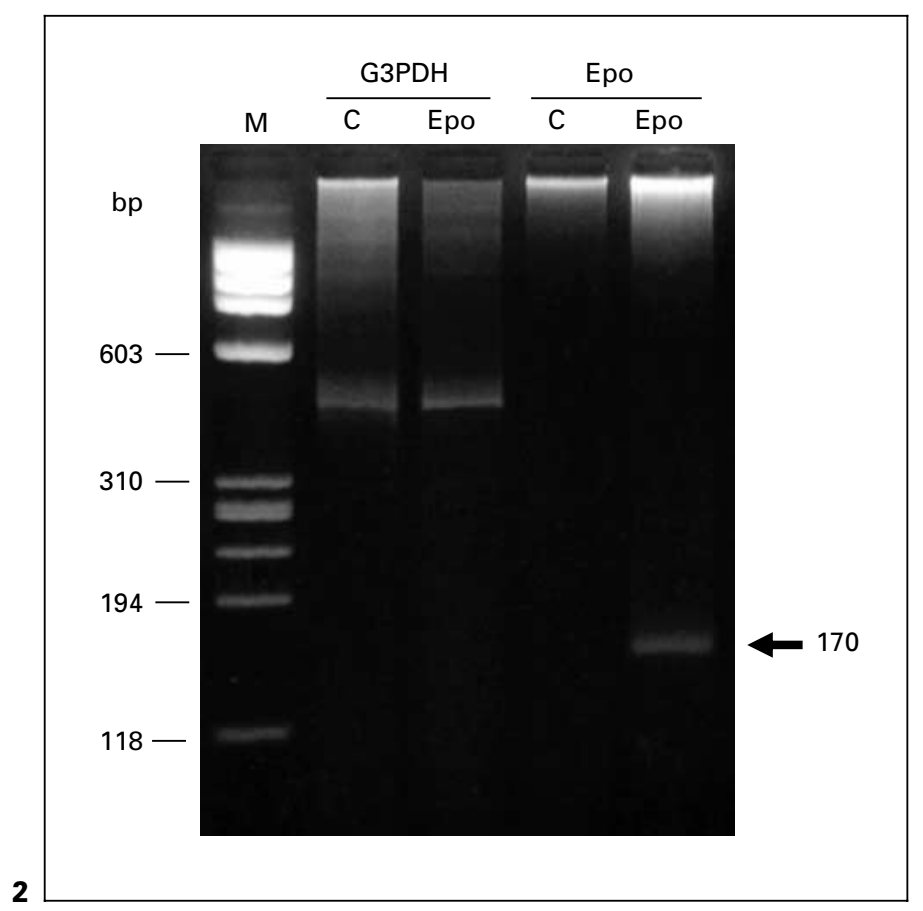

Fig. 2. RT-PCR detection of Epo mRNA in muscle injected with pCAGGS-Epo. Muscles injected with pCAGGS-Epo (lane Epo) or pCAGGS plasmid (lane $\mathrm{C}$ ) were resected 5 days after gene transfer. The RT-PCR products were analyzed by electrophoresis in a $4 \%$ agarose gel. The lengths of the expected products were $170 \mathrm{bp}$ for Epo mRNA and $452 \mathrm{bp}$ for G3PDH mRNA. Lane M is a $\varphi$ X174/HaeIII DNA size marker.

Fig. 3. A Effects of pCAGGS-Epo transfer by in vivo electroporation on serum Epo levels. Epo rats and Control rats were fed a diet containing $0.75 \%$ adenine for 4 weeks. At week 0 , rats were injected with $100 \mu \mathrm{g}$ of pCAGGS-Epo (Epo rats; $\mathrm{n}=7$ ) or pCAGGS (Control rats; $\mathrm{n}=8$ ) in muscles of the lower leg. Electric pulses were delivered to the injection sites. Blood samples were obtained on the indicated weeks after in vivo electroporation and analyzed for Epo by RIA. B Effects on reticulocyte counts of pCAGGS-Epo transfer by in vivo electroporation. C Effects of pCAGGS-Epo transfer by in vivo electroporation on hematocrit levels. Differences between groups were tested by unpaired t tests. ${ }^{*} \mathrm{p}<0.05,{ }^{* *} \mathrm{p}<0.01,{ }^{* * *} \mathrm{p}<0.001$ for comparisons with Normal rats, and ${ }^{\#} \mathrm{p}<0.05$, \#\# $\mathrm{p}<0.01$, \#\# $\mathrm{p}<0.001$ for comparisons with Control rats (comparisons were made within each time point).

\section{White Blood Cell Analysis}

In the present study, changes in the white blood cell counts did not exhibit any consistent trend after the plasmid injection (data not shown).

Epo-Gene Electrotransfer to

Adenine-Induced Renal Failure Rats
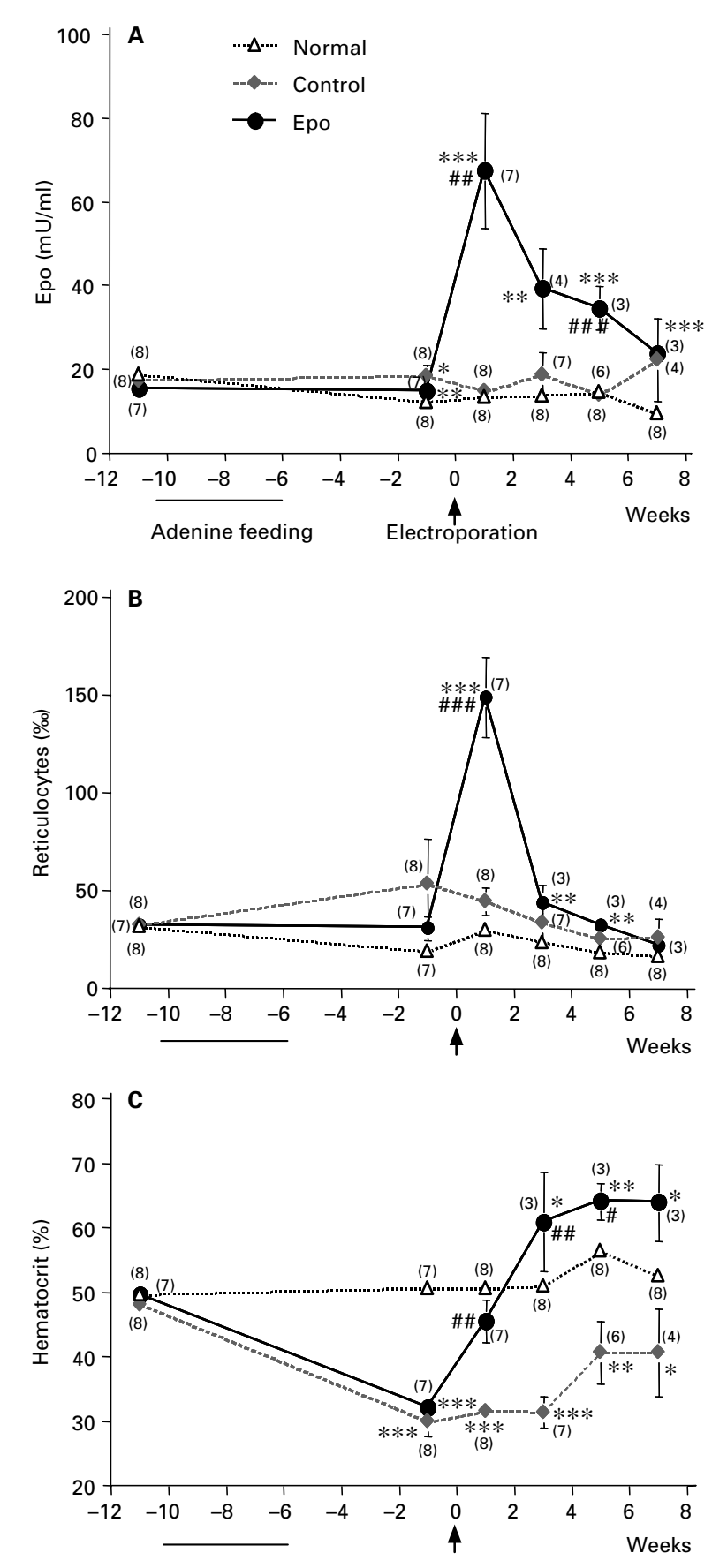

\section{Serum Creatinine Levels}

At week 4 after the end of adenine treatment, the Epo rats $(2.10 \pm 0.25 \mathrm{mg} / \mathrm{dl}, \mathrm{n}=7)$ and Control rats $(2.00 \pm$ $0.19 \mathrm{mg} / \mathrm{dl}, \mathrm{n}=8$ ) showed significantly increased levels of serum creatinine $(\mathrm{p}<0.001)$, compared with Normal rats

Am J Nephrol 2003;23:315-323 


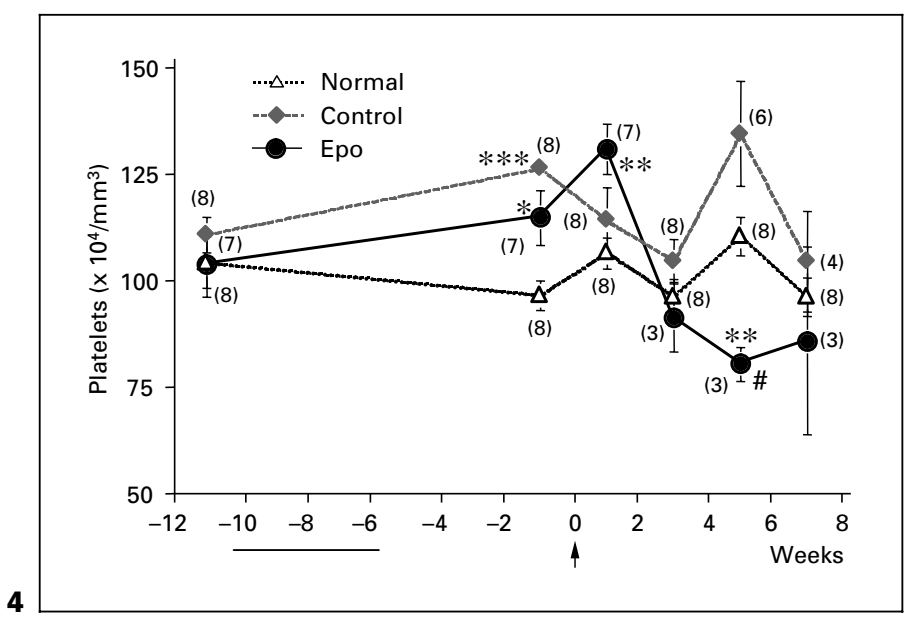

Fig. 4. Changes in platelet counts after adenine administration and pCAGGS-Epo transfer. Differences between groups were tested by unpaired $t$ tests. Each p value is indicated by a symbol, as described in figure 3.

Fig. 5. Changes in serum creatinine levels after adenine administration and pCAGGS-Epo transfer. Differences between groups were tested by unpaired t tests. Each p value is indicated by a symbol, as described in figure 3 .

Fig. 6. Changes in body weight after adenine administration and pCAGGS transfer. Rats were weighed weekly, as indicated in the figure. Differences between groups were tested by unpaired $t$ tests. Each $\mathrm{p}$ value is indicated by a symbol, as described in figure 3 .

$(0.64 \pm 0.02 \mathrm{mg} / \mathrm{dl}, \mathrm{n}=8)$ (fig. 5). Three weeks after pCAGGS-Epo transfer, the serum creatinine levels stopped increasing only slightly and was $1.87 \pm 0.26 \mathrm{mg} /$ $\mathrm{dl}, \mathrm{n}=3$, at week 7 after gene transfer. On the other hand, the renal failure of the Control rats continued to progress during the observation period after pCAGGS transfer $(3.98 \pm 1.30 \mathrm{mg} / \mathrm{dl}, \mathrm{n}=4$, at week 7 after gene transfer).

\section{Growth}

Epo rats weighed $245.4 \pm 6.5 \mathrm{~g}(\mathrm{n}=7)$ at week 4 after the start of adenine treatment (fig. 6), representing about a $20 \%$ reduction in their pre-treatment weight. However, by the end of the experiment, they had regained and even exceeded their pre-treatment weight $(534.0 \pm 45.2 \mathrm{~g}, \mathrm{n}=$ $3)$. Control rats weighed the same as the Epo rats (275.0 \pm $8.3 \mathrm{~g}, \mathrm{n}=8$, at week 4 after the start of adenine treatment
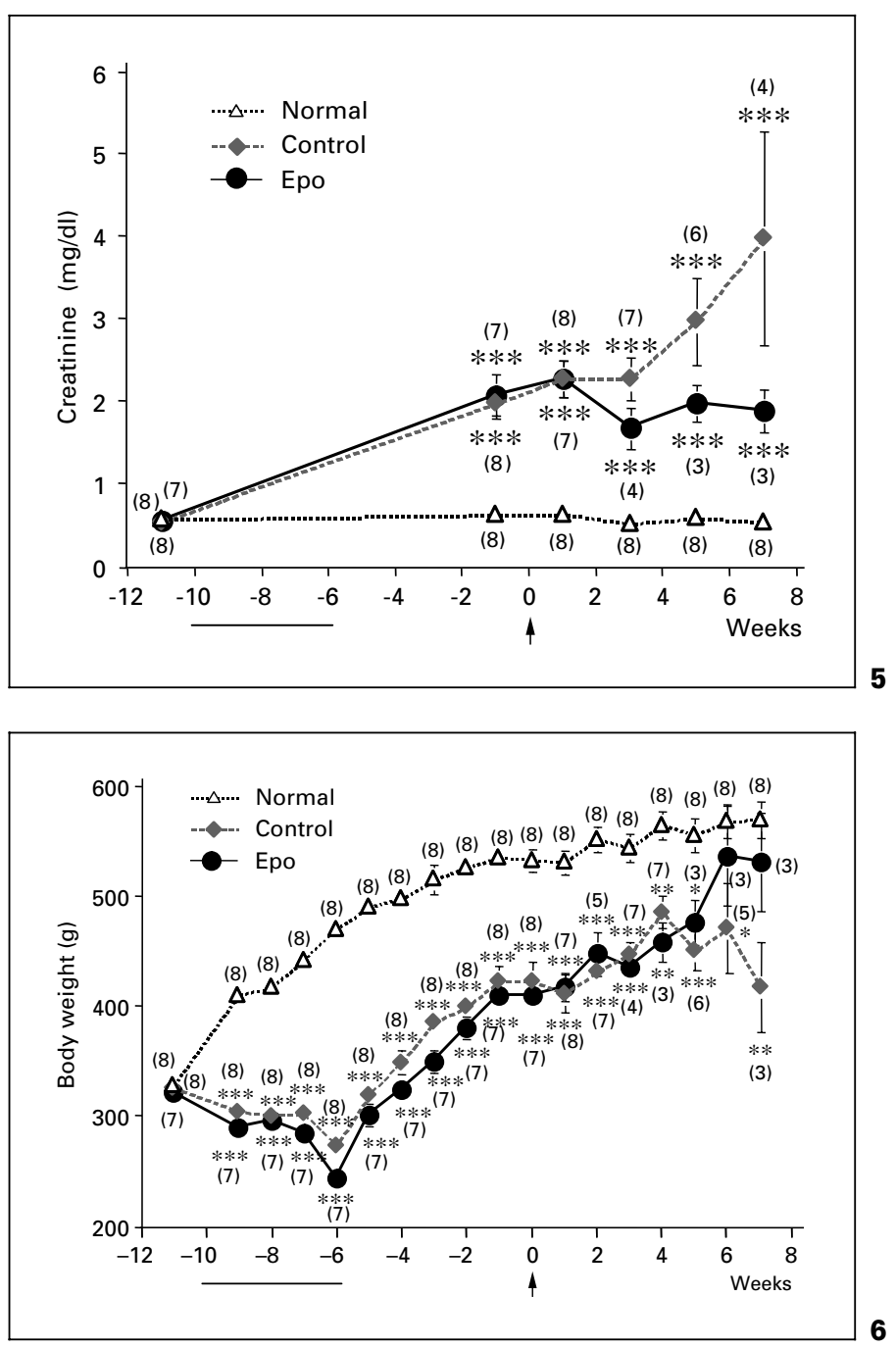

$420.0 \pm 41.2 \mathrm{~g}, \mathrm{n}=3$, at the endpoint of observation). Five weeks after gene transfer, the Epo rats had gained more weight than the Control rats, although the difference was not significant.

\section{Blood Pressure}

Adenine feeding led to gradually increasing blood pressure in the Control rats until the fifth week after pCAGGS transfer (fig. 7). In contrast, before gene transfer, the Epo rats were relatively hypotensive compared with the other groups, up to the point of gene transfer. From 1 week after gene transfer, however, the blood pressure of the Epo rats increased. 


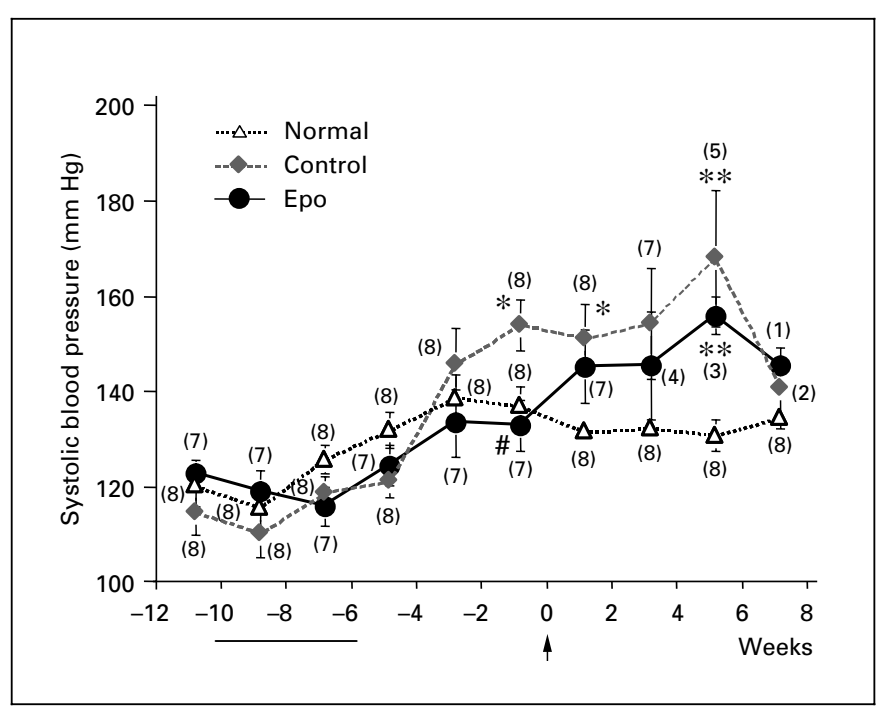

Fig. 7. Effects of pCAGGS-Epo transfer by in vivo electroporation on systolic blood pressure. Blood pressure was measured every other week, as indicated in the figure. Differences between groups were tested by unpaired t tests. Each p value is indicated by a symbol, as described in figure 3 .

\section{Discussion}

The present study demonstrated that in vivo electrotransfer of pCAGGS-Epo improved the severe anemia associated with adenine-induced renal failure in rats. Furthermore, the dose of plasmid DNA used in this experiment did not cause severe adverse effects.

We previously showed that pCAGGS-Epo transfer resulted in the expression of the Epo gene and increased the serum Epo levels in normal rats [8]. We also demonstrated that the Epo gene expression following pCAGGSEpo transfer persisted for more than 11 weeks in normal rats, and for more than 15 weeks in uremic rats, respectively [9]. We used five-sixths nephrectomized rats as animal models of uremia in the previous study [9]. In fivesixths nephrectomized uremic rat model, the hematocrit was mildly decreased to values of $40-50 \%$. Here we have further investigated the effectiveness of the in vivo electroporation method for treating severe anemia, in which the hematocrit levels are equivalent to those in patients with CRF. In support of this evidence, we chose rats with adenine-induced renal failure, which developed severe anemia. The intramuscular administration of pCAGGSEpo increased the serum Epo levels of rats significantly $(\mathrm{p}<0.01)$, compared to Control rats receiving pCAGGS plasmid. The Epo delivery was continuous, lasting for 8 weeks (the endpoint of examination), and induced reticulocytosis, increasing the hematocrit levels, which peaked at $64.5 \pm 4.8 \%$. To avoid polycythemia, the use of smaller doses of pCAGGS-Epo may still improve the anemia associated with renal failure in the adenine-induced uremic rats.

Adenine treatment produces an ideal animal model resembling CRF [11]. However, one-half of the rats died in our present study. It is necessary for further study of CRF that enough numbers of rats have to be prepared, and that the various concentrations and durations of the adenine administration also have to be attempted.

An increase in serum Epo levels can induce hypertension in some cases. We reported previously that the transfer of $400 \mu \mathrm{g}$ of pCAGGS-Epo induced hypertension in uremic rats, but not significantly in normal rats [9]. It has been reported that uremia is necessary for the occurrence of the hypertension associated with the clinical supplementation of rHuEpo [13, 14, 17, 18]. This problem is common and the pathophysiology involves several factors: increased peripheral resistance due to increased blood viscosity, reversal of hypoxic vasodilatation, and a direct effect of Epo. In the present study, after gene transfer, the Epo rats did not show Epo-induced hypertension. The dose we used for electrotransfer $(100 \mu \mathrm{g}$ of pCAGGSEpo) was sufficient for improving the anemia associated with CRF without causing Epo-induced hypertension. For human patients, the appropriate therapeutic doses for treating anemia will have to be adjusted for each individual, because the response to $\mathrm{rHuEpo}$ varies from person to person.

Epoetin $\alpha$, one of the recombinant forms of human Epo, has a direct effect on erythropoiesis, stimulating the proliferation of committed erythroid progenitor cells [13, 19]. We previously demonstrated that pCAGGS-Epo transfer decreased the platelet count in a dose-dependent manner [9]. In fact, thrombocytopenia is a known adverse effect of Epo administration, and may be due to a competition between the precursor cells of the erythrocytic and megakaryotic cell lineages at the stem cell level [23]. In the present study, production of platelets increased at week 1 , and then decreased after week 3 , but our results showed that both increase and decrease of the count was not significant compared with the Control rats.

The Adenine rats showed a decrease in their creatinine level after pCAGGS-Epo transfer. Conversely, Roth et al. [18] reported declines of renal function after rHuEpo injection therapy in patients with ESRD. In fact, we previously showed that the serum creatinine levels of uremic rats increased after Epo gene transfer [9]. It is conceivable 
that this decline in renal function was exacerbated by the existence of Epo-induced hypertension. The gain of ascites and perirenal effusion revealed body weight gain of the Adenine rats. Hence, our present study indicated that renal function was not improved, and that the creatinine levels of the Epo rats were reduced as the reduction of lean body mass from the uremia.

Several groups have reported the application of Epo gene transfer to improving the anemia associated with renal failure. Hamamori et al. [2] showed that the transplantation of Epo-secreting myoblast improved the anemia of nephrectomized mice, with hematocrit levels that increased from 30 to $65 \%$. Osada et al. [24] showed improvement of the severe anemia associated with CRF using DBA/2FG-pcy mice, a model of polycystic kidney disease. The mice in that study had a hematocrit level of $20-25 \%$, and the intraperitoneal administration of recombinant replication-deficient adenoviruses containing human Epo cDNA increased the hematocrit to approximately $45 \%$. More recently, Rizzuto et al. [10] reported that the muscle-targeted electroinjection of plasmid DNA encoding rat Epo improved anemia of nephrectomized rats, hematocrit increased from 40 to $55 \%$. They constructed a plasmid vector encoding the rat Epo cDNA under the control of the cytomegalovirus promoter. When they injected $100 \mu \mathrm{g}$ of the plasmid, the increased hematocrit levels lasted at least 5 weeks; however, a longer period of observation was not feasible because of animal death due to uremia. Our results contribute to the growing body of evidence that indicates Epo gene transfer can be used to improve the anemia associated with CRF. The muscle is suitable tissue for our in vivo electroporation method, because the approach for injection is easy, and effects of Epo gene expression persist for longer period (at least for 8 weeks) compared with the similar method reported by Rizzuto et al. [10]. It is conceivable that the plasmid pCAGGS is more suitable for muscle-targeted gene transfer than their plasmid vector.

In conclusion, the severe anemia of CRF with hematocrits in the 30-35\% range improved after muscle-targeted pCAGGS-Epo transfer by in vivo electroporation. Three weeks after electroporation, the Epo rats showed significant polycythemia with hematocrits over $60 \%$. Further studies must be designed to examine whether smaller doses of pCAGGS-Epo could be effective for improving the anemia associated with $\mathrm{CRF}$, and to identify the best target tissue for gene transfer by in vivo electroporation. And then, in the future, we will be able to treat the anemia using this Epo-gene electrotransfer method in the clinical aspects.

\section{Acknowledgments}

The authors are grateful to N. Imai, K. Yamagiwa, and S. Iguchi (Division of Clinical Nephrology and Rheumatology, Niigata University Graduate School of Medical and Dental Sciences) for technical assistance and advice.

\section{References}

1 Koury MJ, Bondurant MC: Erythropoietin retards DNA breakdown and prevents programmed death in erythroid progenitor cells. Science 1990;248:378-381.

2 Hamamori Y, Samal B, Tian J, Kedes L: Myoblast transfer of human erythropoietin gene in a mouse model of renal failure. J Clin Invest 1995;95:1808-1813.

3 Svensson EC, Black HB, Dugger DL et al: Long-term erythropoietin expression in rodents and non-human primates following intramuscular injection of a replication-defective adenoviral vector. Hum Gene Ther 1997;8: 1797-1806.

4 Osborne WRA, Ramesh N, Lau S, Clowes MM, Dale DC, Clowers AW: Gene therapy for long-term expression of erythropoietin in rats. Proc Natl Acad Sci USA 1995;92:8055-8058.
5 Kessler PD, Podsakoff GM, Chen X et al: Gene delivery to skeletal muscle results in sustained expression and systemic delivery of a therapeutic protein. Proc Natl Acad Sci USA 1996; 93:14082-14087.

6 Tripathy SK, Svensson EC, Black HB et al: Long-term expression of erythropoietin in the systemic circulation of mice after intramuscular injection of a plasmid DNA vector. Proc Natl Acad Sci USA 1996;93:10876-10880.

7 Aihara H, Miyazaki J: Gene transfer into muscle by electroporation in vivo. Nat Biotechnol 1998;16:867-870.

8 Maruyama H, Sugawa M, Moriguchi $\mathrm{Y}$ et al: Continuous erythropoietin delivery by muscletargeted gene transfer using in vivo electroporation. Hum Gene Ther 2000;11:429-437.

9 Maruyama H, Ataka K, Gejyo F et al: Longterm production of erythropoietin after electroporation-mediated transfer of plasmid DNA into the muscles of normal and uremic rats. Gene Ther 2001;8:461-468.
10 Rizzuto G, Cappelletti M, Mennuni C et al: Gene electrotransfer results in a high-level transduction of rat skeletal muscle and corrects anemia of renal failure. Hum Gene Ther 2000; 11:1891-1900.

11 Yokozawa T, Zheng PD, Oura H, Koizumi F: Animal model of adenine-induced chronic renal failure in rats. Nephron 1986;44:230-234.

12 Okada H, Kaneko Y, Yawata T et al: Reversibility of adenine-induced renal failure in rats. Clin Exp Nephrol 1999;3:82-88.

13 Valderrabano F: Erythropoietin in chronic renal failure. Kidney Int 1996;50:1373-1391.

14 Lacasse MS, Kingma I, Lariviere R, Grose JH, Lebel M: Uremia enhances the blood pressure response to erythropoietin. Clin Exp Hypertens 1997;19:389-401.

15 Escbach JW, Adamson JW: Anemia of endstage renal disease. Kidney Int 1985;28:1-5. 
16 NKF-K/DOQI: Clinical practice guidelines for anemia of chronic kidney disease: Update 2000. Am J Kidney Dis 2001;37:S182-S240.

17 Poux JM, Lartigue M, Chaisemartin RA, Galen FX, Leroux-Robert C: Uraemia is necessary for erythropoietin-induced hypertension in rats. Clin Exp Pharmacol Physiol 1995;22. 769-771.

18 Roth D, Smith RD, Schulman G et al: Effects of recombinant human erythropoietin on renal function in chronic renal failure in predialysis patients. Am J Kidney Dis 1994;24:777-784.
19 Markham A, Bryson HM: Epoetin alfa. A review of its pharmacodynamic and pharmacokinetic properties and therapeutic use in nonrenal applications. Drugs 1995;49:232-254.

20 Niwa H, Yamamura K, Miyazaki J: Efficient selection for high-expression transfectants with a novel eukaryotic vector. Gene 1991;108:193199.

21 Ohwada K: Improvement of cardiac puncture in mice (in Japanese). Exp Anim 1986;35:353355.

22 Kuwahara M, Sugano S, Yayou K et al: Evaluation of a new tail-cuff method for blood pressure measurement in rats with special reference to the effects of ambient temperature. Exp Anim 1991;40:331-336.
23 McDonald TP, Clift R, Cottrell MB: Large, chronic doses of erythropoietin cause thrombocytopenia in mice. Blood 1992;80:352-358.

24 Osada S, Ebihara I, Setoguchi Y, Takahshi H, Tomino Y, Koide H: Gene therapy for renal anemia in mice with polycystic kidney using an adenovirus vector encoding the human erythropoietin gene. Kidney Int 1999;55:12341240. 